\title{
AVALIAÇÃO EXPEDITA DA SERAPILHEIRA DE UM FRAGMENTO DE FLORESTA URBANA
}

\author{
EXPEDITE ASSESSMENT OF LITTER FROM A URBAN FOREST FRAGMENT \\ Fernando Vicente Dacól' ${ }^{1}$, Daniela Biondi², Eduardo Praxedes Bomfim Raymundo ${ }^{3}$, \\ Mauricio da Silva Leal ${ }^{4}$, Kelvyn Reksidler ${ }^{5}$
}

\begin{abstract}
RESUMO
Serapilheira é todo o material recém-depositado no solo de uma floresta, podendo indicar o estado de funcionamento da floresta. $O$ objetivo do trabalho foi quantificar e classificar a serapilheira de um fragmento de floresta urbana em diferentes classes: folhas, galhos e cascas, raízes, estruturas reprodutivas e miscelânea (material de difícil distinção). A pesquisa foi realizada ao longo de uma trilha de $750 \mathrm{~m}$ em um fragmento de floresta urbano conhecido por Capão do Tigre, localizado no campus III - Jardim Botânico na Universidade Federal do Paraná. A serapilheira foi coletada por meio de uma amostragem com parcelas de $0,25 \times 0,25 \mathrm{~m}$, a cada $20 \mathrm{~m}$ de distância, adentrado $5 \mathrm{~m}$ da borda da trilha, alternando os lados, para cada parcela. Foram coletadas 30 amostras no percurso da trilha. A serapilheira foi avaliada com base na determinação do peso (úmido e seco) dos seus componentes. A classe galhos e cascas apresentou a maior porcentagem do material coletado (54\%), e diferiu estatisticamente das classes folhas, raízes, estruturas reprodutivas e miscelânea. Os resultados indicam que o fragmento florestal urbano está em estágio avançado de desenvolvimento.
\end{abstract}

Palavras-chave: Ciclagem de nutrientes; Dinâmica da floresta; Capão do Tigre; Biomassa; Deposição.

\begin{abstract}
Litter is all the material recently deposited on the soil of a forest, which may indicate the state of functioning of the forest. The objective of the study was to quantify and classify the litter of a fragment of urban forest in different classes: leaves, branches and barks, roots, reproductive structures and miscellaneous (material difficult to distinguish). The research was carried out along a $750 \mathrm{~m}$ trail in a fragment of urban forest known as Capão do Tigre, located on campus III - Jardim Botânico at the Federal University of Paraná. The litter was collected through sampling with $0.25 \times 0.25 \mathrm{~m}$ plots, every $20 \mathrm{~m}$ away, entering $5 \mathrm{~m}$ from the trailing edge, alternating sides, for each plot. Thirty samples were collected along the trail. The litter was evaluated based on the determination of the weight (wet and dry) of its components. The branch and bark class presented the highest percentage of the collected material (54\%) and differed statistically from the classes leaves, roots, reproductive structures and miscellaneous. The results indicate that the urban forest fragment is in an advanced stage of development.
\end{abstract}

Keywords: Nutrient cycling; Forest dynamics; Capão do Tigre; Biomass; Deposition.

\footnotetext{
Recebido em 08.04.2020 e aceito em 23.07.2020

1 Graduando em Engenharia florestal. Universidade Federal do Paraná. Curitiba/PR. Email: fernando.dacol@gmail.com 2 Engenheira Florestal. Profa. Dra. Universidade Federal do Paraná. Curitiba/PR. Email: danielabiondibatista@gmail.com 3 Graduando em Engenharia florestal. Universidade Federal do Paraná. Curitiba/PR. Email: edupraxedess@gmail.com 4 Graduando em Engenharia florestal. Universidade Federal do Paraná. Curitiba/PR. Email: mauricio.leal.silva@hotmail.com 5 Graduando em Engenharia florestal. Universidade Federal do Paraná. Curitiba/PR. Email: kelv132@hotmail.com
} 


\section{INTRODUÇÃO}

Fragmentos florestais urbanos são remanescentes de florestas alteradas, que devido à expansão das cidades se encontram tanto em perímetro urbano como em ambientes de interface urbano-rural. Podem ser áreas de cobertura arbórea juntamente com outros tipos de vegetação ou áreas urbanas protegidas (BIONDI, 2015). Estes suprem determinadas necessidades dos habitantes, que utilizam esse espaço tanto para lazer e descanso, quanto para atingir metas estabelecidas pelas políticas públicas de uma região (RODRIGUES; PASQUALETTO; GARÇÃO, 2017).

Florestas nativas ou plantios florestais apresentam um contínuo suprimento de material senescente proveniente das partes aéreas ou de raízes das plantas, o que favorece a formação de um horizonte na superfície do solo, também conhecido como serapilheira (CARVALHO et al., 2019). A serapilheira consiste da camada de detritos vegetais (folhas, ramos, caules, cascas, estruturas reprodutivas) e resíduos animais na superfície do solo (VIEIRA; SCHUMACHER, 2010).

A serapilheira é um estoque potencial de nutrientes para o solo, visto que possui papel relevante para a manutenção da fertilidade do sistema edáfico (CALVI et al., 2009), tendo papel importantíssimo no ciclo do carbono, além de movimentar outros nutrientes da vegetação para o solo, onde podem ser reaproveitados pela vegetação (GODINHO et al., 2013).

Fatores como altitude, latitude, precipitação, temperatura, regimes de luminosidade, relevo, disponibilidade hídrica e características do solo afetam a produtividade de serapilheira, sendo que um deles pode se sobressair sobre os demais, dependendo da característica do ecossistema (CALVI et al., 2009). O padrão de decomposição da serapilheira é determinado pelas características da vegetação, pela composição das espécies do ecossistema, pela qualidade dos resíduos da planta, em adição com fatores climáticos que podem alterar a quantidade de serapilheira depositada e acelerar ou não a sua decomposição (VIEIRA; SCHUMACHER, 2010).

A importância de se avaliar a produção e acúmulo da serapilheira está na compreensão do fluxo desse material no ecossistema, fornecendo subsídios para compreensão do funcionamento da transferência de nutrientes e da dinâmica do funcionamento da floresta (FARIAS et al., 2019). Ferreira et al. (2014) salientam que é crucial compreender a dinâmica de funcionamento de florestas secundárias, as quais sofreram impacto assíduo por parte do homem, visto que atualmente estão em pauta discussões sobre políticas de reflorestamento em áreas abandonadas ou modificadas pelo ser humano. O aporte de serapilheira é um serviço ecossistêmico, por ser fundamental na manutenção de nutrientes no sistema, e pode ser indicador de sustentabilidade de uma floresta (SANTANA; SOUTO, 2011). 
O objetivo do presente estudo é quantificar e classificar a serapilheira de um fragmento florestal urbano em diferentes classes para conhecer o seu funcionamento, assim fornecendo subsídios para futuras ações que visem o manejo adequado da área.

\section{MATERIAL E MÉTODOS}

A área de estudo desta pesquisa localiza-se no município de Curitiba, capital do estado

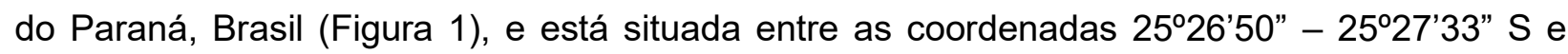
49¹4'16" - 49¹4'33" W, em altitude média de 900 metros (RONDON NETO et al., 2002).

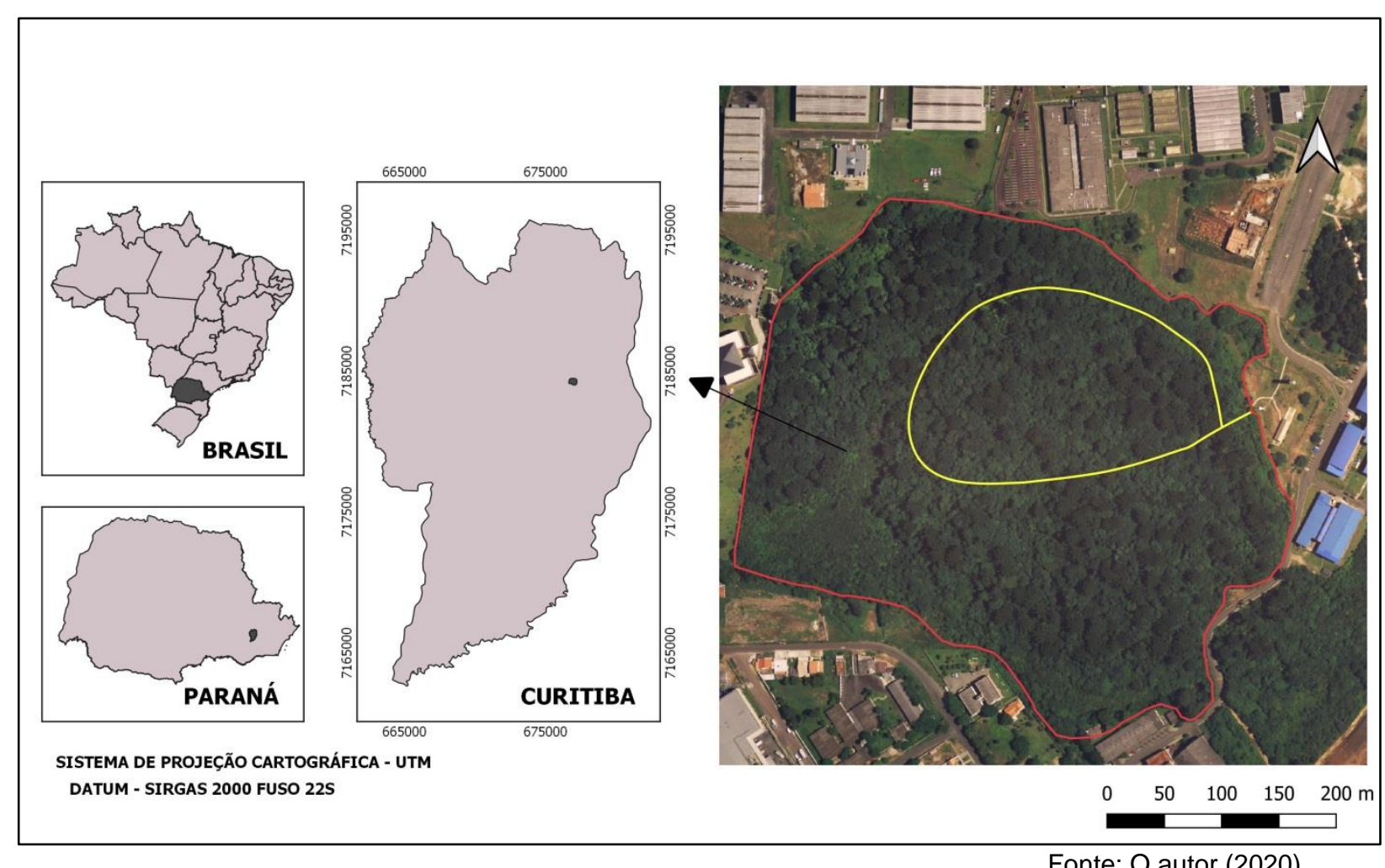

Figura 1. Localização geográfica da cidade de Curitiba, no estado do Paraná, Brasil.

Figure 1. Geographic localization of Curitiba, in state of Paraná, Brazil.

A pesquisa foi realizada num fragmento de floresta urbana conhecido por Capão do Tigre, situado no campus III - Jardim Botânico da Universidade Federal do Paraná, no bairro do Jardim Botânico, Curitiba, Paraná. Possui uma área de 15,2 hectares, dos quais que 12,92 hectares correspondem a Floresta Ombrófila Mista, com a predominância de Araucárias, e 2,28 hectares com nível acentuado de antropização, sobretudo na bordadura do fragmento, com presença marcante de taquaras (AUGUSTYZCZIK, 2011). 
Segundo os tipos climáticos propostos por Köppen e Geiger o local do estudo pertence ao tipo $\mathrm{Cfb}$, clima temperado sem estação seca definida, com verões amenos e invernos com geadas frequentes. Curitiba apresenta uma temperatura média de $17,1^{\circ} \mathrm{C}$, tendo janeiro como seu mês mais quente, com temperatura média de $21^{\circ} \mathrm{C}$, e maio, o mais frio, com temperatura média de $13,4^{\circ} \mathrm{C}$. A cidade apresenta uma precipitação média anual de $1390 \mathrm{~mm}$ (CLIMATE DATA, 2010).

Os solos da região de estudo, reclassificados seguindo as normas do Sistema Brasileiro de Classificação de Solos (2018), são divididos em gleissolos, nas regiões próximas a canais de drenagem, e cambissolos e espodossolos nas regiões drenadas. O relevo é classificado como suave ondulado ( 0 a $8 \%$ de declive) (RONDON NETO et al., 2002).

A pesquisa foi desenvolvida ao longo de uma trilha de 750 metros localizada em uma fração não antropizada de Floresta Ombrófila Mista no fragmento de floresta urbana. A serapilheira foi coletada por meio de amostragem com parcelas de $25 \times 25 \mathrm{~cm}\left(0,0625 \mathrm{~m}^{2}\right)$, a cada 20 metros de distância, adentrando 5 metros da borda, para cada parcela, mesmo que esse fragmento de floresta não tenha interferência antrópica no piso florestal, tomou-se o cuidado de evitar o efeito de borda. O material foi coletado até a condição de que o solo estivesse completamente exposto. Foram estabelecidas 30 parcelas para a realização da pesquisa, seguindo modelo proposto por Carvalho et al. (2019), distribuídas em quatro meses.

As amostras de serapilheira foram coletadas semanalmente entre os meses de abril e julho de 2019, em um único dia, durante as estações de outono e inverno, preferencialmente em dias cuja condição climática fosse favorável às coletas, sem chuvas. A serapilheira coletada foi separada e classificada nas seguintes classes: folhas, galhos e cascas, raízes, estruturas reprodutivas e miscelânea. Na classe estruturas reprodutivas foram incluídas as sementes, flores, inflorescências, frutos e estróbilos. Na classe miscelânea foi incluído todo o material de difícil distinção e classificação em outras classes, devido ao estado de decomposição do material (Figura 2).

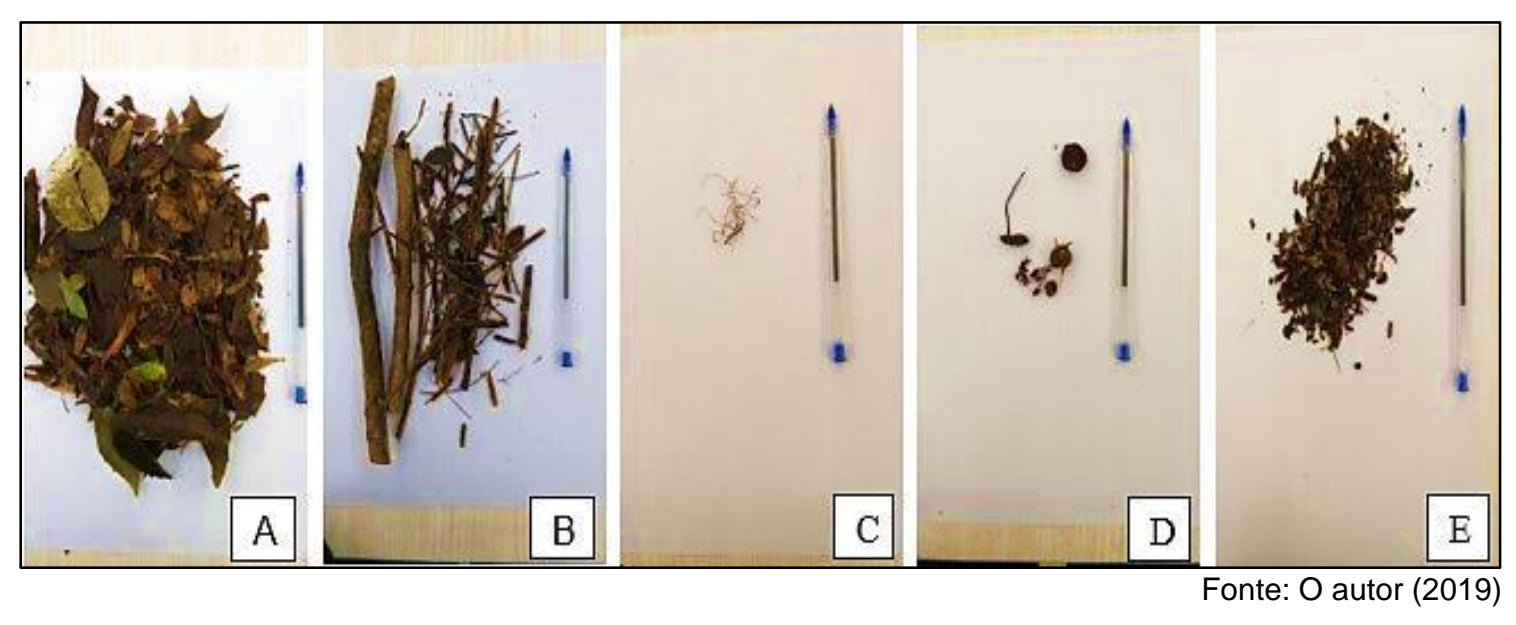


Figura 2. Classificação da serapilheira em folhas (A), galhos e cascas (B), raízes (C), estruturas reprodutivas $(D)$ e miscelânea $(E)$.

Figure 2. Litter classification in leaves $(A)$, branches and barks $(B)$, roots $(C)$, reproductive structures and miscellaneous (E).

Para coleta da serapilheira em campo foram utilizados um gabarito de madeira de dimensões $0,25 \times 0,25 \mathrm{~m}$ (Figura 3), trena de 20 metros, facão, tesoura de poda e sacos plásticos para armazenagem da serapilheira coletada.

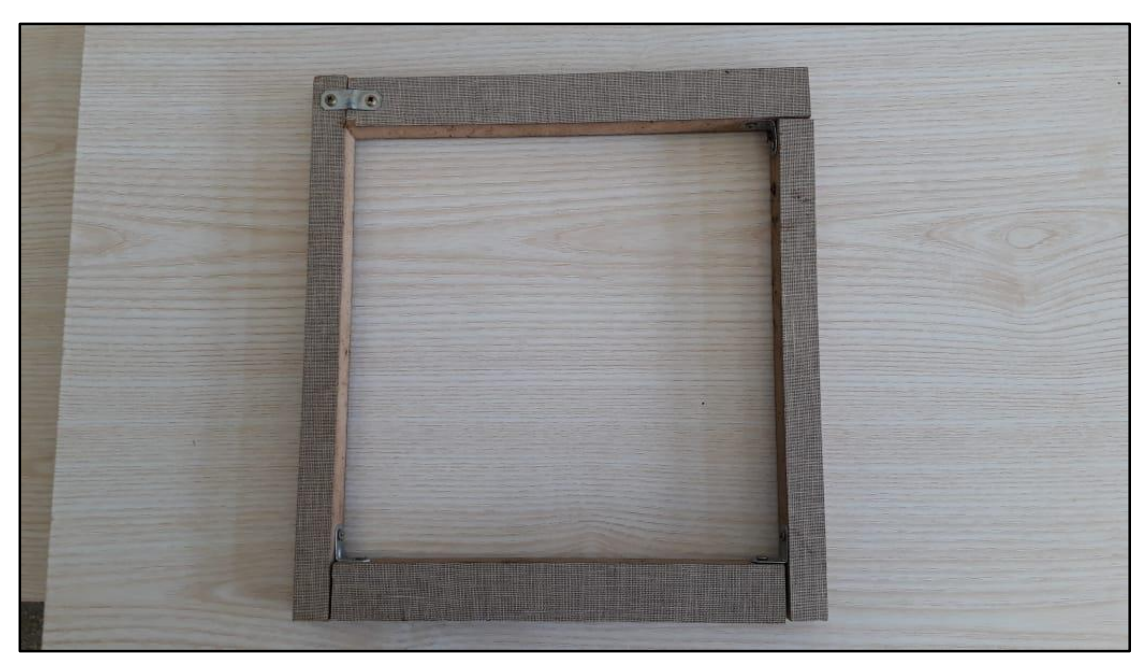

Fonte: O autor (2019)

Figura 3. Gabarito de madeira com dimensões de $0,25 \times 0,25 \mathrm{~m}$ utilizado na coleta de serapilheira. Figure 3. Wood template with $0,25 \times 0,25 \mathrm{~m}$ dimensions used in litter gathering.

O material coletado, depois de separado, foi pesado duas vezes. A primeira, logo após a coleta em campo a fim de determinar o seu peso úmido, variável utilizada para efeitos comparativos, e posteriormente colocado em sacos de papel. A segunda pesagem foi realizada após o material ter sido levado a uma estufa de circulação forçada programada para manter a temperatura constante de $75^{\circ} \mathrm{C}$, por 48 horas, a fim de determinar o peso seco da serapilheira. O peso seco da serapilheira serviu para de fato caracterizar a biomassa da serapilheira, visto que após seco o material apresenta seu peso real. Para ambas as pesagens foi utilizada uma balança mecânica com precisão de décimos de grama. Os dados foram processados com o auxílio do software Microsoft Office Excel e analisados estatisticamente com o auxílio do software Assistat. Para análise estatística foi utilizado o teste SNK, ao nível de 5\% de significância, para as 30 amostras coletadas, relativas às parcelas estabelecidas em campo, em peso seco na unidade de $\mathrm{kg} / \mathrm{ha}$. As classes de serapilheira predefinidas foram definidas como tratamentos na realização do teste. Para cada tratamento foram realizadas 30 repetições, para cada amostra verificou-se a presença de todas as classes de serapilheira. 


\section{RESULTADOS E DISCUSSÃO}

As amostras de serapilheira foram coletadas entre os meses de abril e julho de 2019, durante as estações de outono e inverno e os valores de peso úmido e peso seco da biomassa estão apresentados na Tabela 1. No fragmento florestal de 15 hectares foi amostrada uma área total de $1,87 \mathrm{~m}^{2}$, correspondendo a $776,32 \mathrm{~kg}$ de serapilheira.

Tabela 1. Biomassa de serapilheira $(\mathrm{kg} / \mathrm{ha})$ e percentual de cada classe em relação ao valor total obtido para o peso seco nas amostras coletadas.

Table 1. Litter biomass in $\mathrm{kg} / \mathrm{ha}$ and percentage of each class in relation to the total value obtained for dry value.

\begin{tabular}{cccc}
\hline Classes & Peso úmido $(\mathrm{kg} / \mathrm{ha})$ & Peso seco $(\mathrm{kg} / \mathrm{ha})$ & Peso seco $(\%)$ \\
\hline Folhas & 8638,40 & 3648,00 & 31,33 \\
Galhos e Cascas & 15947,00 & 6297,60 & 54,08 \\
Raízes & 531,20 & 283,20 & 2,43 \\
Estruturas Reprodutivas & 1168,00 & 435,20 & 3,74 \\
Miscelânea & 2060,80 & 980,80 & 8,42 \\
Total & 28345,40 & 11644,80 & 100 \\
\hline
\end{tabular}

A classe galhos e cascas representou a maior parte da serapilheira coletada, com aproximadamente $54 \%$ do total do material, em peso seco (Tabela 1 ).

A alta porcentagem dessa classe contrasta com os valores encontrados por Figueiredo Filho et al. (2003) em estudo realizado em um fragmento de Floresta Ombrófila Mista, na qual os autores encontraram ao final de dois anos de coleta, uma média de 30\% da serapilheira composta por galhos, com produção média de 401,33 kg/ha no outono, e no inverno uma média de $629,94 \mathrm{~kg} / \mathrm{ha}$ representando $29,1 \%$ de toda a serapilheira analisada. A diferença encontrada entre as pesquisas pode ter ocorrido devido à aplicação de metodologias distintas, uma vez que no presente estudo não foram utilizados coletores de serapilheira e o método de parcelas permanentes não foi adotado.

Após realizada análise estatística, verificou-se diferença significativa entre as classes da serapilheira (Tabela 2).

Tabela 2. Comparação entre as médias das classes de serapilheira para o valor de peso seco (ao nível de $5 \%$ de probabilidade).

Table 2. Comparison between the averages of the litter classes for the dry weight value (at the level of $5 \%$ probability).

\begin{tabular}{cc}
\hline \multicolumn{3}{c}{ Classes de serapilheira $(\mathrm{kg} / \mathrm{ha})$} & \\
\hline Folhas & $3648,00 \mathrm{~b}$ \\
& \\
\hline
\end{tabular}




\begin{tabular}{cc} 
Galhos e Cascas & 6297,60 a \\
Raízes & 283,20 c \\
Estruturas Reprodutivas & 435,20 c \\
Miscelânea & 980,80 c \\
\hline Nota: Letras diferentes diferem estatisticamente pelo teste SNK.
\end{tabular}

A comparação de médias confirma estatisticamente a maior presença de galhos e cascas na serapilheira coletada durante o estudo, em relação às demais classes abordadas (Tabela 2). Supõe-se que galhos e cascas por serem estruturas maiores e mais lignificadas sejam de mais difícil decomposição. Heim e Schmidt (2007) afirmam que a lignina é o composto estrutural da serapilheira que apresenta mais difícil decomposição, dada a sua complexidade estrutural, formada por uma cadeia polimérica de anéis aromáticos condensados. Os autores ainda atribuem a decomposição limitada da lignina ao seu nicho restrito de organismos decompositores, como fungos e actinomicetos.

Este resultado pode ainda estar indicando que o fragmento de floresta urbana se encontra em estágio maduro com grande número de árvores adultas, refletindo uma desrama natural de galhos devido principalmente ao sombreamento do local. Rondon Neto et al. (2002) em estudo sobre a caracterização florística e estrutural do Capão do Tigre levantaram variáveis quantitativas, como número de estratos da floresta igual a 3 e área basal superior a $30 \mathrm{~m}^{2} / \mathrm{ha} e$ qualitativas, como presença notável de epífitas. Tais variáveis quando contrastadas com parâmetros determinadores de estágio de sucessão da vegetação da Resolução nº 2 do CONAMA/1994 embasam a tese de que o fragmento está em estágio sucessional intermediário a avançado. Nutto e Spathelf (2003) afirmam que quando um galho é sombreado pela copa que está acima dele ou por vizinhos, ele reduz sua produção fotossintética e é prontamente desconectado do sistema de abastecimento e começa sua senescência em pouco tempo. Os autores alegam ainda que a ineficiência assimilatória e danos abióticos levam as árvores a perder seus galhos.

Barbosa e Faria (2006) em estudo realizado com florestas de diferentes estágios sucessionais na Reserva Biológica de Poço das Antas- RJ encontraram diferença significativa na classe galhos, em que as florestas com 40 e 20 anos de idade estatisticamente produziram mais galhos na serapilheira do que um plantio de 3 anos de idade. Embora o estudo tenha sido realizado em uma fitofisionomia divergente da apresentada em Floresta Ombrófila Mista, é notável a maior presença de galhos na serapilheira de florestas mais maduras, visto que senescência de galhos é maior em áreas com maior competição por luz.

A classe folhas apresentou a segunda maior porcentagem do material coletado, com aproximadamente $31 \%$ de todo o peso seco (Tabela 1). $O$ alto valor atribuído às folhas se deve 
principalmente a presença de folhas da espécie Araucaria angustifolia (Bertol.) Kuntze, que conta com 355 indivíduos no local de pesquisa (MACHADO et al., 2013), principal representante da Floresta Ombrófila Mista com Araucárias na manta do fragmento florestal urbano. Wisniewski et al. (1997) em pesquisa realizada com deposição e decomposição de serapilheira em um trecho de Floresta Ombrófila Mista na região de Ponta Grossa - PR encontraram uma variação entre 49 e $66 \%$ do material coletado, valor maior do que encontrado nessa pesquisa. Em pesquisa realizada por Longhi et al. (2011), com produção e retorno de macronutrientes em três grupos florísticos da FLONA de São Francisco de Paula - RS, os autores encontraram 6301,3 kg/ha/ano de folhas em uma caracterização florística de Floresta Ombrófila Mista típica, tal valor corresponde a mais de $75 \%$ de toda a serapilheira coletada no local de estudo.

A classe folhas diferiu estatisticamente da classe galhos e cascas e das classes raízes, estruturas reprodutivas e miscelânea, da serapilheira coletada (Tabela 2). Barbosa e Faria (2006) encontraram diferença significativa entre as três florestas de diferentes idades (40, 20 e 3 anos), sendo que a floresta de 40 anos de idade apresentou mais folhas em sua serapilheira do que a floresta de 20 anos de idade, ocupando a posição intermediária na análise estatística. Tal resultado suporta a hipótese de que conhecer o estágio sucessional de uma área é fundamental para inferir sobre seu comportamento.

A classe raízes foi responsável por apenas $2 \%$ do total do material coletado, em peso seco, mostrando ser um material pouco presente na serapilheira do solo do fragmento de floresta urbana. Bianchin (2017) em estudo realizado em diferentes fisionomias de Floresta Ombrófila Densa na Reserva Natural de Guaricica localizada no município de Guaraqueçaba - PR, afirma que a maior quantidade de raízes na serapilheira indica que as plantas recuperam nutrientes necessários para seu crescimento na interface serapilheira-solo, antes mesmo de esses nutrientes serem liberados para o solo. A classe raízes se mostrou pouco presente na serapilheira, o que pode implicar em uma menor absorção de nutrientes na fração serapilheira do solo. Embora o presente estudo tenha sido realizado com condições de dinâmica florestal diferentes das apresentadas na Reserva Natural de Guaricica, é possível que as raízes se comportem de maneira similar, tendo em vista a similaridade da quantidade de material radicial coletado em ambos os estudos.

A classe estruturas reprodutivas representou aproximadamente $4 \%$ do total da serapilheira, em peso seco (Tabela 1). Neste período poucas espécies apresentavam estruturas reprodutivas no fragmento de floresta constituído por Floresta Ombrófila Mista. Além disso a pouca existência de estruturas reprodutivas provavelmente se deve ao consumo da fauna local e coleta por humanos (no caso da semente da araucária). Lamberts (2003) afirma que em Florestas com Araucárias muitos animais se alimentam das sementes de A. angustifolia, sendo eles invertebrados, ou mais comumente vertebrados, como aves e pequenos roedores. Bianchin 
(2017) constata que o material reprodutivo é de fácil decomposição, principalmente órgãos reprodutivos não lignificados.

Para a classe miscelânea, foi encontrado o valor de $8 \%$ de toda a serapilheira coletada (Tabela 1). No estudo realizado por Figueiredo Filho et al. (2003) foi encontrado o valor de 247,66 $\mathrm{kg} / \mathrm{ha}$ de miscelânea para o outono representando 18,5\% do total de serapilheira coletada, e 252 $\mathrm{kg} /$ ha para o inverno, caracterizando $11,5 \%$ do total do material. A menor percentagem de miscelânea encontrada neste estudo pode ser explicada devido ao maior número de classes de serapilheira em relação aos outros estudos, tais como: Wisniewski et al. (1997) e Figueiredo Filho et al. (2003), nos quais a estratificação da serapilheira era composta por folhas, galhos e miscelânea, e materiais como estruturas reprodutivas e raízes eram atribuídos à miscelânea.

As classes raízes, estruturas Reprodutivas e miscelânea não diferiram estatisticamente entre si (Tabela 2) e apresentam papel coadjuvante no total da serapilheira coletada. Em estudo realizado por Barbosa e Faria (2006) houve diferença estatística entre o material reprodutivo de florestas com diferentes idades, sendo a floresta de 20 anos de idade a maior produtora desse material, seguida pela floresta de 40 anos e de 3 anos de idade. Supõe-se que florestas em estágios intermediários a avançado produzam mais material reprodutivo que florestas em estágios iniciais.

O presente estudo detectou uma anormal presença da classe galhos e cascas em relação às demais classes na serapilheira do fragmento florestal, fato que diverge de todos os estudos comparativos utilizados na discussão, nos quais a classe folhas se mostrava mais presente dentre a serapilheira. Para sanar essa questão devem ser elaborados estudos que acompanhem a deposição de serapilheira por mais tempo, com a finalidade de detectar se há padrão na maior incidência de galhos e cascas na serapilheira de um fragmento florestal urbano. A pesquisa apresenta dados essenciais para o melhor entendimento do funcionamento da floresta e serve como base para futuros estudos no local.

\section{CONCLUSÕES}

Com os resultados obtidos conclui-se que a classe galhos e cascas somada a classe folhas são responsáveis por $85,41 \%$ da serapilheira do fragmento de floresta urbano Capão do Tigre, caracterizando amplo domínio dessas classes sobre as demais, evidenciado pela análise estatística realizada no estudo. Com a evidência da maior presença da classe galhos e cascas, foi detectado um possível funcionamento florestal divergente em relação a demais áreas em que foram realizados estudos sobre serapilheira, assim novas pesquisas devem ser realizadas no local para identificar os possíveis motivos da soberania desta classe, para assim garantir melhor inferência sobre a dinâmica local. 
Foi possível constatar a escassez de pesquisas sobre serapilheira em fragmentos florestais urbanos, dificultando a realização de comparações com os resultados obtidos. Nesse contexto recomenda-se o desenvolvimento de mais pesquisas sobre serapilheira em fragmentos florestais urbanos, para melhor compreensão de suas dinâmicas.

\section{AGRADECIMENTOS}

Ao CNPq - Conselho Nacional de Pesquisa pelo financiamento desta pesquisa através da bolsa de Iniciação Científica (IC-CNPq).

\section{REFERÊNCIAS}

AUGUSTYNCZIK, A. L. D. Avaliação do tamanho de parcelas e intensidades de amostragem para a estimativa de estoque e estrutura horizontal em um fragmento de Floresta Ombrófila Mista. 2011. 164 p. Dissertação (Mestrado em Engenharia Florestal) - Universidade Federal do Paraná, Curitiba, 2011.

BARBOSA, J. H. C.; DE FARIA, S. M. Aporte de serapilheira ao solo em estágios sucessionais florestais na reserva biológica de Poço das Antas, Rio de Janeiro, Brasil. Rodriguésia, Rio de Janeiro, v. 56, n. 3, p. 461-476, 2006.

BIANCHIN, J. E. Dinâmica da serapilheira e atributos microbiológicos do solo em um gradiente altudinal de floresta atlântica. 2017. 167 p. Tese (Doutorado em Engenharia Florestal) - Universidade Federal do Paraná, Curitiba, 2017.

BIONDI, D. Fragmentos Florestais e Áreas Protegidas Urbanas. In: . Floresta Urbana.

Curitiba: A autora, 2015. p. 29-49.

CALVI, G. P.; PEREIRA, M. G.; ESPÍNDULA JÚNIOR, A. Produção de serapilheira e aporte de nutrientes em áreas de Floresta Atlântica em Santa Maria de Jetibá, ES. Ciência Florestal, Santa Maria, v. 19, n. 2, p. 131-138, 2009.

CARVAlho, F. F.; GARCIA, P. A. B. B.; ARAGÃO, M. A.; VIRGENS, A. P. Litterfall and Litter decomposition in Pinus and Native Forests. Floresta e Ambiente, Rio de Janeiro, v. 26, n. 3, p.1-10, 2019.

CARVALHO, H. C. S.; FERREIRA, J. L. S.; CALIL, F. N.; SILVA-NETO, C. M. Estoque de nutrientes na serapilheira acumulada em quatro tipos de vegetação no Cerrado em Goiás, Brasil. Ecologia e Nutrição Florestal, Santa Maria, v. 7, n. 6, p.1-11, 2019.

CLIMATE-DATA. Clima: Curitiba. 2010. Disponível em: <https://pt.climatedata.org/location/2010/>. Acesso em: 12 de julho de 2019.

DACANAL, C; LABAKI, L. C.; SILVA, T. M. L. Vamos passear na floresta! O conforto térmico em fragmentos florestais urbanos. Ambiente construído, Porto Alegre, v. 10, n. 2, p. 115-132, 2010. 
FARIAS, D. T.; BARRETO, F. R. S.; SOUZA, M. R.; SILVA, C. J. Serapilheira em fragmento florestal de caatinga arbustivo-arbórea fechada. Revista Verde, Pombal, v. 14, n. 2, p. 331-337, 2019.

FERREIRA, M. L.; MORAES, G. F.; PEREIRA, E. E.; LAMANO-FERREIRA, A. P. N. Litter fall production and decomposition in a fragment of secondary atlantic forest of São Paulo, SP, southeastern Brazil. Revista Árvore, Viçosa, v. 38, n. 4, p. 591-600, 2014.

FIGUEIREDO FILHO, A.; SILVA, J. L.; SCHAAF, L. B.; DE FIGUEIREDO, D. J. Avaliação estacional da deposição de serapilheira em uma floresta ombrófila mista localizada no sul do estado do Paraná. Ciência Florestal, Santa Maria, v. 13, n. 1, p. 11-18, 2003.

GODINHO, T. O.; CALDEIRA, M. V. W.; CALIMAN, J. P.; PREZOTTI, L. C.; WATZLAWICK, L. F.; AZEVEDO, H. C. A.; ROCHA, J. H. T. Biomassa, macronutrientes e carbono Orgânico na serapilheira depositada em trecho de floresta Estacional Semidecidual Submontana, ES. Scientia Forestalis, Piracicaba, v. 41, n. 97, p. 131-144, 2013.

HEIM, A.; SCHMIDT, M. W. I. Lignin turnover in arable soil and grassland analysed with two different labelling approaches. European Journal of Soil Science, Zurique, v.58, p.599-608, 2007.

LAMBERTS, A. V. D. H. Predação e sobrevivência de sementes de Araucaria angustifolia (Bert.) Kuntze em áreas de mata nativa e plantação de Pinus eliotti na Floresta Nacional de São Franscisco de Paula, RS. 2003. 76 p. Dissertação (Mestrado em Ecologia) Universidade Estadual de Campinas, Campinas, 2003.

LONGHI, R. G.; LONGHI, S. J.; CHAMI, L. B.; WATZLAWICK, L. F.; EBLING, A. A. Produção de serapilheira e retorno de macronutrientes em três grupos florísticos de uma Floresta Ombrófila Mista, RS. Ciência Florestal, Santa Maria, v. 21, n. 4, p. 699-710, 2011.

MACHADO, S. A.; ZAMIN, N. T.; NASCIMENTO, R. G. M.; AUGUSTYNCZIK, A. L. D.; MENEGAZZO, C. S. Comparação dos parâmetros fitossociológicos entre três estratos de um fragmento de floresta ombrófila mista. Cerne, v. 19, n. 3, p. 365-372, 2013.

NUTTO, L.; SPATHELF, P. Modelagem da desrama natural de Araucaria angustifolia (Bert.) O. Ktze. Revista Floresta, Curitiba, v. 33, n. 3, p. 295-309, 2003.

RODRIGUES, A. P. M.; PASQUALETTO, A.; GARÇÃO, A. L. O. A influência dos parques urbanos no microclima de Goiânia. Revista Brasileira de Assuntos Regionais e Urbanos, Goiânia, v. 3, n. 1, p. 25-44, 2017.

RONDON NETO, R. M.; KOZERA, C.; DE ANDRADE, R. R.; CECY, A. T.; HUMMES, A. P.; FRITZSONS, E.; CALDEIRA, M. V. W.; MACIEL, M. N. M.; DE SOUZA, M. K. F. Caracterização florística e estrutural de um fragmento de floresta ombrófila mista, em Curitiba, PR - Brasil. Revista Floresta, Curitiba, v.32, n.1, p. 3-16, 2002.

SANTANA, J. A. S.; SOUTO, J. S. Produção de serapilheira na caatinga da região semiárida do Rio Grande do Norte, Brasil. IDESIA, Arica, v. 29, n. 2, p. 87-94, 2011.

VIEIRA, M.; SCHUMACHER, M. V. Teores e aporte de nutrientes na serapilheira de Pinus taeda L., e sua relação com a temperatura do ar e pluviosidade. Revista Árvore, Viçosa, v. 34, n. 1, p. 85-94, 2010. 
VIEIRA, M.; SCHUMACHER, M. V. Variação mensal da deposição de serapilheira em povoamento de Pinus taeda L. em área de campo nativo em Cambará do Sul - RS. Revista Árvore, Viçosa, v. 34, n. 3, p. 487-494, 2010.

WISNIEWSKI, C.; RIBAS, M. E.; KRIEGER, A.; CURSIO, G. Produção e decomposição da serapilheira e deposição de nutrientes em um trecho de uma Floresta Ombrófila Mista sobre Latossolo Vermelho-escuro, no segundo planalto Paranaense. In: CONGRESSO BRASILEIRO DE CIÊNCIAS DO SOLO. SOCIEDADE BRASILEIRA DE CIÊNCIAS DO SOLO, 26., 1997, Rio de Janeiro. Anais ... Rio de Janeiro: Sociedade Brasileira de Ciência do Solo, 1997. 